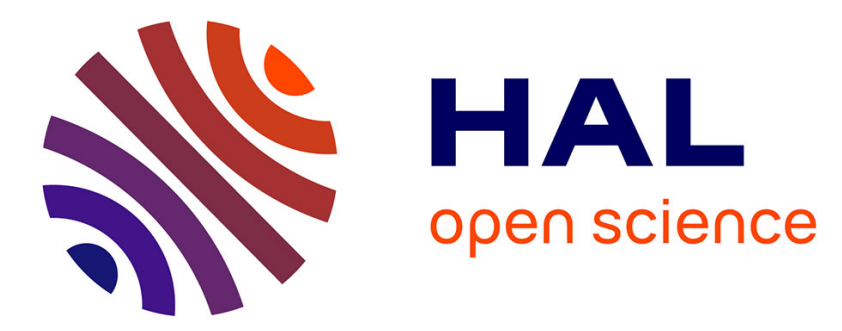

\title{
Medical management, prevention and mitigation of environmental risks factors in Neurology
}

\author{
J. Reis, G.C. Román, M. Giroud, V.S. Palmer, P.S. Spencer
}

\section{To cite this version:}

J. Reis, G.C. Román, M. Giroud, V.S. Palmer, P.S. Spencer. Medical management, prevention and mitigation of environmental risks factors in Neurology. Revue Neurologique, 2019, 175, pp.698 - 704. 10.1016/j.neurol.2019.10.001 . hal-03488521

\section{HAL Id: hal-03488521 \\ https://hal.science/hal-03488521}

Submitted on 21 Dec 2021

HAL is a multi-disciplinary open access archive for the deposit and dissemination of scientific research documents, whether they are published or not. The documents may come from teaching and research institutions in France or abroad, or from public or private research centers.
L'archive ouverte pluridisciplinaire HAL, est destinée au dépôt et à la diffusion de documents scientifiques de niveau recherche, publiés ou non, émanant des établissements d'enseignement et de recherche français ou étrangers, des laboratoires publics ou privés.

\section{다)(1) $(5$}

Distributed under a Creative Commons Attribution - NonCommerciall 4.0 International 


\title{
Medical management, prevention and mitigation of environmental risks factors
} in Neurology

\author{
J. Reis a,b,*, G.C. Román ${ }^{\mathrm{c}, \mathrm{d}}$, M. Giroud ${ }^{\mathrm{e}}$, V.S. Palmer ${ }^{\mathrm{f}}$ and P.S. Spencer ${ }^{\mathrm{f}}$ \\ ${ }^{\text {a }}$ University of Strasbourg, Department of Neurology, University Hospital of Strasbourg, \\ France \\ ${ }^{\mathrm{b}}$ Association RISE, 3 rue du loir, Oberhausbergen 67205 France \\ ${ }^{c}$ Department of Neurology, Methodist Neurological Institute and Research Institute, Houston \\ Methodist Hospital, Houston, Texas, USA \\ ${ }^{\mathrm{d}}$ Weill Cornell Medical College, Cornell University, New York, NY, USA \\ ${ }^{\text {e }}$ Dijon Stroke Registry, EA 7460, University of Bourgogne-Franche Comté, INSERM, Santé \\ Publique France, University Hospital of Dijon. France. \\ ${ }^{\mathrm{f}}$ Department of Neurology, School of Medicine, Oregon Health \& Science University, \\ Portland, Oregon, USA
}

*Corresponding author:

Jacques Reis, University of Strasbourg, Department of Neurology, University Hospital of Strasbourg, 1 Place de l'Hôpital, 67000 Strasbourg, France jacques.reis@wanadoo.fr 


\begin{abstract}
The human environment and exposures arising therefrom are major contributors to neurological disorders ranging from stroke to neurodegenerative diseases. Reduction of exposure to environmental risk factors, with the goal of disease prevention or control, is addressed at the individual as well as the societal level and in recognition of differential subject vulnerability. We examine some practical solutions in high-income countries that may allow a better adaptation to environmental risks and reduce their adverse impact on the nervous system. We consider the citizen's role in reducing unhealthy exposures and explore new approaches to treatment.
\end{abstract}

\title{
Keywords
}

Risk management, indoor air, microbiome, diet, chelation, health policy 


\section{Introduction}

Protection of human health is the mandate of Neurology, as with any other branch of Medicine although, in practice and of necessity, the focus is often placed on human disease. Clinicians are required to diagnose, treat and thereby control or cure disease, while researchers more often seek causation so disease can be dissected, controlled or prevented. While primary disease prevention is the goal of all who practice Neurology, if the disease is already smouldering, secondary intervention at a subclinical stage has great merit, too. Alas, eventually all medical efforts will fail because life is a terminal condition, but it is surely better to die with disease than from disease. The question is what causes disease to begin in the first place, and the answer appears to be the interaction of factors internal and external to the human body, where the first is controlled by the genome/epigenome and the second by the exposome, meaning the totality of exogenous influences from conception forward.

We address issues related to the management, prevention and mitigation of environmental risks factors relevant to neurologists, to the extent they apply to adults living in mostly highincome countries. We underline the concepts of vulnerability and risk management, of which risk assessment is an integral component. We examine possible therapeutic solutions that may allow for better adaptation to these risks and even a remediation of their adverse effects on the human brain. Personalised medical advice and public health policies are scrutinized, as well as the influence of citizens' concerns in health-policy decisions.

\section{Basic concepts}

\subsection{Environmental risk factors}

The pragmatic analysis of the human environment has given rise to the epidemiological concept of risk factor, albeit with the understanding that association between $\mathrm{X}$ and $\mathrm{Y}$ does not mean $\mathrm{X}$ causes $\mathrm{Y}$. Environmental risk factors are thus selected components of the exposome that are associated with adverse effects on the human organism and its health, wellbeing and longevity. Those risk factors interact in complex ways with the genome/epigenome to impact health and generate disease [1].

\subsection{Vulnerability}

The Merriam-Webster dictionary defines human vulnerability as: "capable of being physically or emotionally wounded, and open to attack or damage" [2]. Vulnerability is questionable in medical ethics and even philosophy. [3] The general characteristic of vulnerability is used for 
several objects, both man-made (infrastructures, financial world, etc.) as well as biological or ecological systems. Due to the differences among humans, identifying one or more vulnerable populations at risk [4], and the sources of that vulnerability, becomes a major goal in interventional public health.

\subsection{Risk Management}

The identification and analysis of risk factors should be followed by the formulation and application of preventive measures or precautionary procedures. This is the classical method used in many fields (technologies, financial world, etc.) to mitigate risk and control exposure. In Neurology, such methods have led to education and personal prevention tools. The Stroke Riskometer is a good example [5] because it helps to target the main risk factors for each person. In the general population, disease prevention is conducted by public health policy. For identified at-risk population groups, specific interventions are widely used to foster health and minimize disease risk. These include, for example, chemical-specific guidelines for permissible workplace exposures, prophylactic interventions to support key metabolic needs (e.g., supplementation with iodine, vitamin D, folic acid, etc.), and vaccination for the purposes of primary disease prevention. The goals are multiple, such as the reduction of neurological handicap, lowering morbidity, and increasing life expectancy.

\section{Medical interventions and treatments for preventive actions}

Air quality is an important issue for health maintenance. In the case of ambient (outdoor) air pollution, a risk factor for several neurological disorders, notably stroke, disease prevention must be addressed at global, regional and local political levels. By contrast, the quality of indoor air can be controlled to a significant extent by individual choice. We examine this subject and others relating to exposures relating to personal behaviours.

\subsection{Improvement of indoor air quality}

In westernised countries, the richer populations may spend up to $90 \%$ of their time in confined spaces (home, professional settings, cars, etc). The quality of indoor air is thus a major issue, especially for the elderly who are confined indoors. In these settings, indoor air quality is substantially dependent on the optimal operation of heating, ventilating and sometimes air-conditioning systems (HVAC). New HVAC technologies have been developed and are now available. In the absence of contaminants, intelligent systems that monitor and 
regulate air quality can create a pristine indoor environment [6]. The "smart home is a residence equipped with a high-tech network, linking sensors and domestic devices, appliances, and features that can be remotely monitored, accessed or controlled, and provide services that respond to the needs of its inhabitants» [7]. This evolved from an optimization perspective of energy use, ventilation technology and building construction (low-energy and passive houses) to a more global approach that also addresses the comfort and well-being of its inhabitants [8] irrespective of the presence of airborne particulate matter and higher temperatures of external air [9]. The quality of the indoor environment also varies with factors such as mould, animal hair, and chemical pollutants, notably tobacco smoke. Certain volatile organic pollutants can be addressed by phytoremediation, namely the deployment of potted plants as botanical biofilters [10-11]. This contrasts sharply with the poor quality of indoor air in certain low-income settings where indoor, unventilated wood stoves are often used for cooking and heating [12].

\subsection{Targeting brain and mind: From physical and intellectual exercise to environmental issues (Back-to-Nature).}

\subsubsection{Cognitive training is a familiar recommendation}

However, its real effectiveness remains controversial, particularly in age-associated cognitive decline and neurodegenerative conditions such as Alzheimer's disease $[13,14]$.

\subsubsection{Beneficial effects of regular physical exercise are well documented}

On the contrary, the beneficial effects of regular physical exercise are well documented [1517], in particular when the exercise program is performed in a natural environment and outdoors [18]. The therapeutic effect of "healing in and through nature" led to a little-known discipline in the West called "forest medicine." This was developed in Japan and spread to Korea and China [19-21]. The effect of an environment perceived as healthy becomes a new approach to "well-being" leading to objective anti-stress effects [22]. Recently, this new nature therapy or Shinrin-Yoku (forest-bathing) has gained interest beyond Asian countries. A recent review concludes that this method "offers humans an authentic way of healing and health prevention for the mind, body and spirit" [23].

In Western countries, the health and well-being effects of natural environments with green and blue spaces, in particular forest [24], have also been established, notably in urban areas, and not only for their impacts on air pollution and urban heat islands [25-26]. 


\subsubsection{Thermalism / balneotherapy / immersion in hot springs}

This therapeutic and preventive medical approach may be compared with thermalism / balneotherapy / immersion in hot springs, used in many countries across the world [27].

\subsection{Improving the metabolism: the role of medications, diet, functional food and aromatherapy.}

\subsubsection{Natural substances}

There is great interest in the potential of natural substances and the repositioning of several existing pharmaceutical products (glutamate antagonists, antioxidants, trophic factors) for health maintenance and control of neurological disorders, including many neurodegenerative diseases [28-29]. This search for "environment-mimetic" drugs appears to be a theoretically promising approach, although still experimental [30-31].

\subsubsection{Several diets}

Several diets including the Mediterranean, ketogenic, and Japanese diet, as well as the DASH (Dietary Approaches to Stop Hypertension) diet, have been extensively investigated leading to official recommendations by different governmental agencies [32 -34] according to the pathologies presented by the patients (i.e., hypertension, hyperlipemia, diabetes mellitus) [4043].

\subsubsection{Extensive nutritional research}

Extensive nutritional research focused also on the role of dietary supplements (trace elements, iodine and omega 3), vitamins (e.g. folic acid, vitamins D and E) [35-36]. Several fruits (e.g. berries, nuts), vegetables (e.g. cocoa) and derived food (wine, oil) which contain specific nutrients (e.g. polyunsaturated fatty acids or PUFAs, polyphenols, anthocyanins, flavonoids) have been assessed or should be for several neurodegenerative diseases, stroke and cognition [37-45]. This preventive role of specific foods and nutrients clearly shows that diet is a perfect modifiable environmental risk factor! Of course, the use of organic food [46], e.g. extravirgin olive oil (see accompanying reviews), increases the benefits.

However, the deleterious effect of some foods, such as trans fats, constantly underlined [47] has to be also considered. Caution is also needed because many plants and mushrooms, especially those found in wild settings, contain substances that can generate acute and possibly chronic neurological disease [48]. While of primary relevance in low-income settings 
food use of certain wild mushrooms (False Morels) is currently under investigation in regard to sporadic amyotrophic lateral sclerosis in the West [49].

\subsubsection{Herbal medicine}

Herbal medicine is the use of herbs (e.g. mint family, rose) and essentials oils. Herbs act as functional food combined or not with aromatherapy, topically or by inhalation, and/or by ingestion. Herbs and essential oils contain terpenes and terpenoids which have a therapeutic potential. $[50,51]$. Beyond these examples is a vast world of plant-based medicine, whether formalized as in Chinese Traditional Medicine or Ayurvedic Medicine, or as practiced today as in yesteryear across impoverished populations of Africa and beyond.

\subsection{A new target, the gut microbiome: nutrition and pollution impact}

\subsubsection{Gut microbiome}

There is rapidly growing scientific interest in the role of the gut microbiome in health and disease [52,53]. This concept is recent although it has been developing since the 1800s [54, 55]. The current notion emphasizes the interaction with the microbiome of every food item ingested, in addition to their purely nutritional aspects [56, 57]. On the other hand, several studies investigating pollution and notably air pollution have shown that the gut microbiome is impacted [58-60]. Recently, it has been proposed that microbial metabolites may enter the systemic circulation and epigenetically reprogram the expression of host genes in the CNS, regulating neuroinflammation, cell survival, or cell death [61].

\subsubsection{Microbiome-Gut-Brain Axis}

Along with its major role in health and diseases [62], the discovery of the Microbiome-GutBrain Axis will probably modify our understanding of neurodegenerative and neurodevelopmental diseases [63-69]. Therefore, it is conceivable that the gut microbiome may become a major therapeutic target to mitigate the impact of environmental pollutants on the brain. Having an efficient and healthy gut microbiome to protect the brain may become a public health recommendation. Along these lines, the role of prebiotics (a substrate that is selectively utilized by host micro-organisms and confers a health benefit) probiotics ("live micro-organisms which, when administered in adequate amounts, confer a health benefit on the host") and fibers, for example, has become a major research area [56, 70-76].

\subsubsection{Highly neurotoxic chemicals from substances stored in plants}


These promising developments notwithstanding, we need to keep in mind that gut flora have the potential to generate highly neurotoxic chemicals from substances stored in plants used for food. The classic example is the generation of the potent developmental genotoxin methylazoxymethanol from its glucoside cycasin, the leading candidate for Western Pacific amyotrophic lateral sclerosis and parkinsonism-dementia [77]. Many plants used for food across the world harbour pro-toxins, such as cyanogenic glucosides, that are activated to neurotoxic species (e.g. hydrogen cyanide) by the action of intestinal bacteria [48].

\subsection{When risks are unavoidable: Specific treatments for environmentally-induced diseases and new therapeutic approaches.}

\subsubsection{Metal chelators}

The therapeutic use of metal chelators has specific indications to treat metabolic inherited overload diseases (e.g., Wilson disease) as well as intoxications from occupational or accidental overexposure [78- 81]. A robust toxicological assessment of the poisoning is mandated prior to the therapeutic use of chelation because chelating chemicals are not metal-specific and may have serious side effects.

\subsubsection{Chelators for less-clear indications}

The spreading trend to use chelators for less-clear indications such as symptoms attributed to heavy metal exposures (fibromyalgia and chronic fatigue syndrome) raises concerns regarding misuse [82, 83]. These indications are neither validated nor lacking side effects (although poorly documented) [84]. Thus "alternative medicine" offers detoxification treatments in response to fear and concerns arising from the awareness of the global chemical contamination, which is very real issue. The Internet provides extensive but largely unreliable information and advertisements for sites ranging from "heavy metals detox diet" to "detoxification with sodium, 2,3-dimercaptopropanesulfate (DMPS) or the 2,3-dimercaptosuccinic acid (DMSA) FDA-approved medicine" [85]. This medical advertising seems to be allowed in the USA as long as no treatment results are promised (avoiding false advertisement punishable by law). Controversies about the safety of dental amalgam (which contains $>50 \%$ elemental mercury by weight) fuelled the debate a decade ago because of the possible health impact of the constant mercury release [86,87]. Both a scientific consensus and the use of the Precautionary principle are needed as health effects of organic mercury are possible [88]. Since this debate, dental amalgams have been largely replaced by other materials.

\subsubsection{Chelators might become useful new therapeutics}


Despite these controversies, chelators might become useful new therapeutics; iron chelators are under experimental and clinical investigation in Parkinson disease and neurodegenerative diseases [89-93]. Although the effect of classical chelators ethylene diamine tetra acetic acid (EDTA) for manganese intoxication are well known [94], the repositioning of an old drug para-aminosalicylic acid (PAS) with few side effects, offers new perspectives for the treatment of manganese-induced Parkinsonism as shown by experimental data $[95,96]$.

\section{From individual responsibility to public health policy}

\subsection{Health education and promotion}

Managing environmental risks in Neurology is no different from other medical fields. The process begins with the person's responsibility to follow health recommendations and medical advice, as well as adoption of low-risk behaviours. Thus, health education and promotion (e.g. non-smoking attitude, better nutrition, favouring non-contact sports) are key elements for improving individual behaviours and living conditions.

\subsection{Management strategies should be adapted to local conditions}

Given that health and environmental policies have permanency, the management strategies should be adapted to local conditions. They should consider ethical issues e.g. utility, fairness, and accountability for reasonableness [97] as in general, vulnerable and low-income groups have more risk factors. Therefore, these issues should focus on pure risk management [98], as well as on the use of cost-effectiveness methods [99]. Societies, their political representatives and international institutions have immense responsibility to improve and defend the economic well-being of their citizens (fighting against poverty), to provide environmental safety (reduction of the pollution of the commons: water and air) and to take actions to promote health and well-being (regulations of smoking and pesticides). International professional organisations also have a large responsibility; the European Stroke Organisation promoted an action plan for stroke in Europe, 2018-2030 [100], promoting legislative changes, media campaigns, labelling of food and educational and preventive measures in schools, workplaces and the community, on physical activity, tobacco consumption, food quality, psychosocial risk factors and air pollution.

\subsection{Sociological changes}

Moreover, sociological changes are occurring. The on-going trend, launched in the 1960s to "return to nature", emphasizes consumption of organic food and a more "traditional' living 
style [101]. First addressed by the upper social classes, this issue is now supported by younger people in Europe. Thus, a recent event is raising awareness and concern for the environment, and notably for its relationship to climate change $[102,103]$. Europe's young citizens are now becoming active stakeholders!

\section{Quo Vadis}

The biomedical community has a special responsibility for health promotion and disease prevention, because of its foundation in scientific knowledge and ethics. As experts, we can emphasize the usefulness of translational approaches, especially if we engage with and learn from communities. One model might be the Japanese National Center for Neurology and Psychiatry in Tokyo [104], where, researchers interact with clinicians and patients. In this unique campus, neurologists and psychiatrists can consider, with patients' input, the diverse factors relating to complex health disorders, such as Irritable Bowel Syndrome, a subject rarely addressed by neurologists elsewhere. Another approach that can benefit the patient population is closer interaction between the practicing clinician and biomedical scientist in a manner that exploits their diverse approaches and complementary understanding of neurological disorders.

These and other approaches can help address the threats to human health posed by environmental risk factors and contribute to their effective management.

\section{Disclosure of interest}

The authors declare that they have no competing interest. 


\section{References}

1 Reis J., Román G.C. Environmental neurology: A promising new field of practice and research. J. Neurol. Sci. 2007; 262: 3-6

2 Definition of vulnerability https://www.merriam-webster.com/ dictionary/ vulnerability Accessed 14.07.2019

3 Boldt $\mathbf{J}$. The concept of vulnerability in medical ethics and philosophy. Philosophy, Ethics, and Humanities in Medicine. 2019; 14: 6

4 Anderson UM, Jenss R, Mosher WE, Randall CL, Marra E. High-risk groups, definition and identification. N Engl J Med. 1965; 273: 308-13.

5 Feigin VL, Norrving B. A new paradigm for primary prevention strategy in people with elevated risk of stroke. Int. J Stroke. 2014; 9: 624-6

6 Cociorva S, Iftene A. Indoor air quality evaluation in intelligent building. Energy Procedia. 2017; 112: $261-68$

7 Marikyan D., Papagiannidis S. and Alamanos E. "A systematic review of the smart home literature: A user perspective," Technological Forecasting and Social Change. 2019; 138: 13954

8 Schieweck A, Uhde E., Salthammer T. et al. Smart homes and the control of indoor air quality. Renew Sustain Energy Rev. 2018; 94: 705-18

9 Salthammer T., Schieweck A., Gu J., Ameri S., Uhde E. Future trends in ambient air pollution and climate in Germany - Implications for the indoor environment. Build. Environ. 2018; 143: 661-70

10 Pettit T, Irga PJ, Torpy FR. Towards practical indoor air phytoremediation: A review. Chemosphere. 2018; 208: 960-74

11 Teiri H, Pourzamani H, Hajizadeh Y. Phytoremediation of VOCs from indoor air by ornamental potted plants: A pilot study using a palm species under the controlled environment. Chemosphere. 2018; 197: 375-81

12 Improving health, nutrition, and population outcomes in Sub-Saharan Africa: the role of The World Bank. WB, Washington DC. 2004; p:243. http://documents.worldbank.org/curated/en/592281468198873970/Improving-healthnutrition-and-population-outcomes-in-Sub-Saharan-Africa-The-Role-of-the-World-Bank Accessed 14.07.2019

13 A. Bahar-Fuchs, L. Clare and B. Woods, Cognitive training and cognitive rehabilitation for mild to moderate Alzheimer's disease and vascular dementia, Cochrane Database Syst. Rev. 2013; 6: CD003260, 1-106 
14 E.L. Kallio, H. Öhman, H. Kautiainen, M. Hietanen and K. Pitkälä, Cognitive Training Interventions for Patients with Alzheimer's Disease: A Systematic Review, J Alzheimers Dis. 2017; 56: 1349-72

15 J.E. Ahlskog. Does vigorous exercise have a neuroprotective effect in Parkinson disease? Neurology. 2011; 77: 288-94

16 T. Seifert, Exercise and neurologic disease. Continuum (Minneap Minn), Sports Neurol. 2014; 20: 1667-82

17 Mayo Clinic Staff Exercise: 7 benefits of regular physical activity. https://www.mayoclinic.org/healthy-lifestyle/fitness/in-depth/ exercise /art-20048389 Accessed 05-05-2018

17 Rabin JS, Klein H, Kirn DR, Schultz AP, Yang HS, Hampton O et al. Associations of Physical Activity and $\beta$-Amyloid with Longitudinal Cognition and Neurodegeneration in Clinically Normal Older Adults. JAMA Neurology, 2019; DOI: 10.1001/jamaneurol.2019.1879

18 J.T. Coon, K. Boddy, K. Stein, R. Whear, J.R. Barton and M.H. Depledge. Does Participating in Physical Activity in Outdoor Natural Environments Have a Greater Effect on Physical and Mental Wellbeing than Physical Activity Indoors? A Systematic Review, Environ Sci. Technol. 2014; 45: 1761-72.

19 B.J. Park, Y. Tsunetsugu, T. Kasetani, T. Kagawa and Y. Miyazaki. The physiological effects of Shinrin-Yoku (taking in the forest atmosphere or forest bathing): evidence from field experiments in 24 forests across Japan, Environ Health Prev. Med. 2010; 15: 18-26.

20 H. Ochiai, H. Ikei, C. Song, M. Kobayashi, A. Takamatsu, T. Miura, et al., Physiological and psychological effects of forest therapy on middle-aged males with high-normal blood pressure. Int. J Environ Res Public Health. 2015; 12: 2532-42.

21 Karjalainen E, Sarjala T, Raitio H. Promoting human health through forests: overview and major challenges. Environ Health Prev Med. 2010; 15: 1-8

22 K. Husk, R. Lovell, C. Cooper, W. Stahl-Timmins and R. Garside. Participation in environmental enhancement and conservation activities for health and well-being in adults: a review of quantitative and qualitative evidence, Cochrane Database Syst. Rev. 2016; 5: CD010351, [p256].

23 Hansen MM, Jones R, and Tocchini K. Shinrin-Yoku (Forest Bathing) and Nature Therapy: A State-of-the-Art Review. Int. J Environ Res Public Health. 2017; 14: 851 
24 López-Pousa S, Bassets Pagès G, Monserrat-Vila S, de Gracia Blanco M, Hidalgo Colomé J, Garre-Olmo J. Sense of Well-Being in Patients with Fibromyalgia: Aerobic Exercise Program in a Mature Forest-A Pilot Study.

Evid Based Complement Alternat Med. 2015; 2015: 614783.

25 Aerts R, Honnay O, Van Nieuwenhuyse A. Biodiversity and human health: mechanisms and evidence of the positive health effects of diversity in nature and green spaces. Br Med Bull. 2018; 127: 5-22.

26 Kabisch N, van den Bosch M, Lafortezza R. The health benefits of nature-based solutions to urbanization challenges for children and the elderly - A systematic review. Environ Res. 2017; 159: 362-73.

27 Gálvez I, Torres-Piles S, Ortega-Rincón E. Balneotherapy, Immune System, and Stress Response: A Hormetic Strategy? Int J Mol Sci. 2018; 19: pii: E1687.

28 Habtemariam S. Natural Products in Alzheimer's Disease Therapy: Would Old Therapeutic Approaches Fix the Broken Promise of Modern Medicines? Molecules. 2019 Apr 17;24. pii: E1519.

29 Vajda, F.J. Neuroprotection and neurodegenerative disease, J Clin. Neurosci. 2002; 9: 4-8. 30 Nithianantharajah J. and A.J. Hannan, Enriched environments, experience-dependent plasticity and disorders of the nervous system, Nat Rev Neurosci. 2006; 7: 697-709.

31 McOmish CE, Hannan AJ. Enviromimetics: exploring gene- environment interactions to identify therapeutic targets for brain disorders. Expert Opin. Ther. Targets 2007; 11:899-913. 32 Estruch R, Ros E, Salas-Salvadó J, Covas MI, Corella D, Arós F, et al. PREDIMED Study Investigators. Primary prevention of cardiovascular disease with a Mediterranean diet. N Engl J Med. 2013; 368: 1279-90.

33 Kokubo Y, Padmanabhan S, Iwashima Y, Yamagishi K and Goto A. Gene and environmental interactions according to the components of lifestyle modifications in hypertension guidelines Environ Health Prev Med. 2019; 24:19

34 Pinto A, Bonucci A, Maggi E, Corsi M, Businaro R. Anti- Oxidant and Anti-Inflammatory Activity of Ketogenic Diet: New Perspectives for Neuroprotection in Alzheimer's Disease. Anti-oxidants (Basel). 2018; 28: 1-16, pii: E63.

35 E.M. Mowry, D. Pelletier, Z. Gao, M.D. Howell, S.S. Zamvil and E. Waubant, Vitamin D in clinically isolated syndrome: evidence for possible neuroprotection. Eur J Neurol. 2016; 23: 327-32.

36 Reimers A, Ljung $\mathrm{H}$. The emerging role of omega-3 fatty acids as a therapeutic option in neuropsychiatric disorders. Ther. Adv. Psychopharmacol. 2019; 9: 1-18. 
37 R. Venkatesan, E. Ji and S.Y. Kim, Phytochemicals that regulate neurodegenerative disease by targeting neurotrophins: a comprehensive review. BioMed Research Inter 2015; 814068.

38 Subash S, Essa MM, Al-Adawi S, Memon MA, Manivasagam T, Akbar M. Neuroprotective effects of berry fruits on neurodegenerative diseases. Neural Regen Res. 2014; 9: 1557-66.

39 Manolescu BN, Oprea E, Mititelu M, Ruta LL, Farcasanu IC. Dietary Anthocyanins and Stroke: A Review of Pharmacokinetic and Pharmacodynamic Studies. Nutrients. 2019; 11:135.

40 Ullah R, Khan M, Shah SA, Saeed K, Kim MO. Natural Antioxidant Anthocyanins-A Hidden Therapeutic Candidate in Metabolic Disorders with Major Focus in Neurodegeneration. Nutrients. 2019;11. pii: E1195.

41 Socci V, Tempesta D, Desideri G, De Gennaro L, Ferrara M. Enhancing Human Cognition with Cocoa Flavonoids. Front Nutr. 2017; 4: 19.

42 Calderón-Garcidueñas L, San Juan Chávez V, Vacaseydel-Aceves NB, Calderón-Sánchez R, Macías-Escobedo E, Frías C, et al. Chocolate, Air Pollution and Children's Neuroprotection: What Cognition Tools should be at Hand to Evaluate Interventions ? Front Pharmacol. 2016; 7: 232.

43 Lehert P, Villaseca P, Hogervorst E, Maki PM, Henderson VW. Individually modifiable risk factors to ameliorate cognitive aging: a systematic review and meta-analysis. Climacteric. 2015;18: 678-89.

44 Seidl SE, Santiago JA, Bilyk H, Potashkin JA. The emerging role of nutrition in Parkinson's disease. Front Aging Neurosci. 2014; 6: 36.

45 Sherzai AZ, Tagliati M, Park K, Pezeshkian S, Sherzai D. Micronutrients and Risk of Parkinson's Disease: A Systematic Review. Gerontol. Geriatr. Med. 2016; 2:1-11.

46 Mie A, Andersen HR, Gunnarsson S, Kahl J, Kesse-Guyot E, Rembiałkowska E, Quaglio $\mathrm{G}$ et al. Human health implications of organic food and organic agriculture: a comprehensive review. Environ Health. 2017; 16: 111

47 Kokubo Y, Higashiyama A, Watanabe M and Miyamoto Y. A comprehensive policy for reducing sugar beverages for healthy life extension. Environ Health Prev Med. 2019; 24:13 48 Palmer VS, Tshala-Katumbay, D.D. Spencer P.S. Plants with neurotoxic potential in undernourished subjects. 2019 Rev Neurol (Paris) in press

49 Spencer PS, Lagrange E, Camu W. ALS and environment: clues from spatial clustering. Rev Neurol (Paris). 2019 Jun 20 pii: S0035-3787(19)30604-6. 
50 Kumar Y, Prakash O, Tripathi H, Tandon S, Gupta MM, Rahman LU et al. AromaDb: A Database of Medicinal and Aromatic Plant's Aroma Molecules with Phytochemistry and Therapeutic Potentials. Front Plant Sci. 2018; 13: 1081.

51 Agatonovic-Kustrin S, Kustrin E, Morton DW. Essential oils and functional herbs for healthy aging. Neural Regen Res. 2019; 14: 441-5.

52 National Academies of Sciences, Engineering, and Medicine. Environmental Chemicals, the Human Microbiome, and Health Risk: A Research Strategy. The National Academies Press, Washington, DC. 2018. Page 122. http://nap.edu/24960 Accessed 14.07.2019

53 The Human Microbiome Project Consortium. A framework for human microbiome research. Nature. 2012; 486: 215-21.

54 Anonymous. Microbiomes: An Origin Story. 2019 March 8,

https://www.asm.org/Articles/2019/March/Microbiomes-An-Origin-Story\#.XSsLK1ANRNs

Accessed 14.07.2019

55 Prescott SL. History of medicine: Origin of the term microbiome and why it matters. Human Microbiome Journal. 2017; 4: 24-5

56 Oriach CS, Ruairi C. Robertson RC, Catherine Stanton C, Cryan JF, Dinan TG. Food for thought: The role of nutrition in the microbiota-gut brain axis. Clinical Nutrition Experimental. 2016; 6: 25-38.

57 Pace LA, and Crowe SE. Complex Relationships Between Food, Diet and the Microbiome. Gastroenterol Clin North Am. 2016; 45: 253-65

58 Salim SY, Kaplan GG, Madsen KL. Air pollution effects on the gut microbiota: a link between exposure and inflammatory disease. Gut Microbes. 2014 ; 5 : 215-9.

59 Jin Y, Wu S, Zeng Z, Fu Z. Effects of environmental pollutants on gut microbiota. Environ Pollut. 2017; 222: 1-9.

60 Vallès Y. \& Francino M.P. Air Pollution, Early Life Microbiome, and Development. Curr Environ Health Rep. 2018; 5: 512-21.

61 Dempsey JL, Little M, Cui J. Gut microbiome: an intermediary to neurotoxicity. Neurotoxicology. 2019; pii: S0161-813X (19)30080-4.

62 Wang B, Yao M, Lv L, Ling Z, Li. The Human Microbiota in Health and Disease. Engineering. 2017; 3: 71-82

63 O'Mahony SM, Clarke G, Dinan TG, Cryan JF. Early-life adversity and brain development: Is the microbiome a missing piece of the puzzle? Neuroscience. 2017; 342: 3754. 
64 Sharon G, Sampson TR, Geschwind DH, Mazmanian SK. The Central Nervous System and the Gut Microbiome. Cell. 2016; 167: 915-32.

65 Ghaisas S, Maher J, Kanthasamy A. Gut microbiome in health and disease: Linking the microbiome-gut-brain axis and environmental factors in the pathogenesis of systemic and neurodegenerative diseases. Pharmacol Ther. 2016; 158: 52-62.

66 Keshavarzian A, Green SJ, Engen PA, Voigt RM, Naqib A, Forsyth CB et al. Colonic bacterial composition in Parkinson's disease. Mov Disord. 2015; 30:1351-60.

67 Chiang HL, Lin CH. Altered Gut Microbiome and Intestinal Pathology in Parkinson's Disease. J Mov Disord. 2019; 12: 67-83.

68 Dinan TG, Stilling RM, Stanton C, Cryan JF. Collective unconscious: How gut microbes shape human behavior. Journal of Psychiatric Research. 2015; 63:1-9.

69 Srikantha P, Mohajeri MH. The Possible Role of the Microbiota-Gut-Brain-Axis in Autism Spectrum Disorder. Int J Mol Sci. 2019; 20:1-28.

70 Voreades N, Kozil A, Weir TL. Diet and the development of the human intestinal microbiome. Front Microbiol. 2014; 5: 494.

71 Watkins C, Stanton C, Ryan CA, Ross RP. Microbial Therapeutics Designed for Infant Health. Front Nutr. 2017; 4: 48.

72 Gibson GR, Hutkins R, Sanders ME, Prescott SL, Reimer RA, Salminen SJ et al. Expert consensus document: The International Scientific Association for Probiotics and Prebiotics (ISAPP) consensus statement on the definition and scope of prebiotics. Nat Rev Gastroenterol Hepatol. 2017; 14: 491-502.

73 Feng P, Ye Z, Kakade A, Virk AK, Li X, Liu P. A Review on Gut Remediation of Selected Environmental Contaminants: Possible Roles of Probiotics and Gut Microbiota. Nutrients. 2018; 11: 1-22.

74 Cantu-Jungles TM, Rasmussen HE and Hamaker BR. Potential of Prebiotic Butyrogenic Fibers in Parkinson's Disease Front Neurol. 2019; 10:1-8.

75 Cerdó T, Ruíz A, Suárez A, Campoy C. Probiotic, Prebiotic, and Brain Development. Nutrients. 2017; 9. pii: E1247.

76 Makki K, Deehan EC, Walter J, Bäckhed F. The Impact of Dietary Fiber on Gut Microbiota in Host Health and Disease. Cell Host Microbe. 2018; 23: 705-715.

77 Spencer P.S. Hypothesis: Etiologic and molecular mechanistic leads for sporadic neurodegenerative diseases based on experience with Western Pacific ALS/PDC. Front Neurol. 2019; 10: 754.

78 Weiss KH, Thurik F, Gotthardt DN, Schäfer M, Teufel U, Wiegand F et al. 
Efficacy and safety of oral chelators in treatment of patients with Wilson disease. Clin Gastroenterol Hepatol. 2013; 11: 1028-35.

79 Sears ME. Chelation: Harnessing and Enhancing Heavy Metal Detoxification-A Review. Scientific World Journal. 2013; 18; 2013: 219840.

80 Aaseth J, Skaug MA, Cao Y, Andersen O. Chelation in metal intoxication--Principles and paradigms. J Trace Elem Med Biol. 2015; 31: 260-6.

81 Bjørklund G, Mutter J, Aaseth J. Metal chelators and neurotoxicity: lead, mercury, and arsenic. Arch Toxicol. 2017; 91:3787-97.

82 Charles A. McKay Jr. Editorial: Use and Misuse of Metal Chelation Therapy. J. Med. Toxicol. 2013; 9: 301-2

83 Charles A. McKay, Jr. Introduction to Special Issue: Use and Misuse of Metal Chelation Therapy J. Med. Toxicol. 2013; 9: 298-300

84 Allen J, Montalto M, Lovejoy J, Weber W. Detoxification in naturopathic medicine: a survey. J Altern Complement Med 2011; 17: 1175-80.

85 Hyman M. How to get rid your body of heavy metals: A 3-step detoxification plan. https://drhyman.com/blog/2010/05/19/how-to-rid-your-body-of-mercury-and-other-heavy-

metals-a-3-step-plan-to-recover-your-health/ Accessed 14.07.2019

86 Mutter J, Naumann J, Sadaghiani C, Walach H, Drasch G. Amalgam studies: disregarding basic principles of mercury toxicity. Int. J Hyg Environ Health. 2004; 207: 391-7.

87 Mutter J. Is dental amalgam safe for humans? The opinion of the scientific committee of the European Commission. J Occup Med Toxicol. 2011; 6: 2.

88 Vearrier D, Greenberg MI. Care of patients who are worried about mercury poisoning from dental fillings. J Am Board Fam Med. 2010; 23: 797-8.

89 Youdim MB, Stephenson G, Ben Shachar D. Ironing iron out in Parkinson's disease and other neurodegenerative diseases with iron chelators: a lesson from 6-hydroxydopamine and iron chelators, desferal and VK-28. Ann N Y Acad. Sci 2004; 1012: 306-25.

90 Youdim MBH Monoamine oxidase inhibitors, and iron chelators in depressive illness and neurodegenerative diseases. J Neural Transm (Vienna). 2018;125: 1719-1733.

90 López-Pousa S, Bassets Pagès G, Monserrat-Vila S, de Gracia Blanco M, Hidalgo Colomé J, Garre-Olmo J. Sense of Well-Being in Patients with Fibromyalgia: Aerobic Exercise Program in a Mature Forest-A Pilot Study.

Evid Based Complement Alternat Med. 2015; 2015: 614783.

91 Ward RJ, Dexter DT, Crichton RR. Neurodegenerative diseases and therapeutic strategies using iron chelators. J Trace Elem Med Biol. 2015; 31: 267-73. 
92 Martin-Bastida A, Ward RJ, Newbould R, Piccini P, Sharp D, Kabba C et al.

Brain iron chelation by deferiprone in a phase 2 randomised double-blinded placebo controlled clinical trial in Parkinson's disease. Sci Rep. 2017; 7: 1-9.

93 Sun Y, Pham AN, Waite TD. Mechanism Underlying the Effectiveness of Deferiprone in alleviating Parkinson's Disease Symptoms. ACS Chem. Neurosci. 2018; 9:1118-27

94 Crossgrove J. and Zheng W. Manganese toxicity upon overexposure. NMR Biomed. 2004; 17: 544-53

95 Zheng W, Jiang YM, Zhang Y, Jiang W, Wang X, and Cowan DM.

Chelation Therapy of Manganese Intoxication with para- Aminosalicylic Acid (PAS) in Sprague-Dawley Rats. Neurotoxicology. 2009; 30: 240-8.

96 Li SJ, Meng HY, Deng XF, Fu X, Chen JW, Huang S et al. Protective effects of sodium paminosalicylic acid on learning and memory via increasing the number of basal forebrain choline acetyltransferase neurons in manganese-exposed rats. Hum Exp Toxicol. 2015; 34: 240-8.

97 Resnik DB, MacDougall DR, Smith EM. Ethical Dilemmas in Protecting Susceptible Subpopulations. From Environmental Health Risks: Liberty, Utility, Fairness, and Accountability for Reasonableness. Am J Bioeth. 2018; 18: 29-41

98 Jardine C, Hrudey S, Shortreed J, Craig L, Krewski D, Furgal C et al.

Risk management frameworks for human health and environmental risks.

J Toxicol Environ Health B Crit Rev. 2003; 6: 569-720.

99 Schlander M. The use of cost-effectiveness by the National Institute for Health and Clinical Excellence (NICE): not (yet) an exemplar of a deliberative process. J Med Ethics 2008; 34: 534-9.

100 Norrving B, Barrick J, Davalos A, Dichgans M, Cordonnier C, Guekht A et al. Action Plan for stroke in Europe, 2018-2030. European Stroke Journal. 2018; 3: 309- 36.

101 O'Brien K, Selboe E, and Hayward B. M. Exploring youth activism on climate change: dutiful, disruptive, and dangerous dissent. Ecology and Society 2018; 23:42.

102 Aiello M. Functional Foods: Between New Consumption Trends and Renewed Perceptions of Health. Italian Sociological Review. 2011;1: 45-58.

103 Ward P, Coveney J, and Henderson J. Editorial: A sociology of food and eating. Why now? Journal of Sociology. 2010; 46: 347-51.

104 Pamphlet of the National Center for Neurology and Psychiatry. https://www.ncnp.go.jp/pdf/center_pamph_en.pdf Accessed 14.07.2019 